\title{
Comparison of Serum Lipid Profile in Diabetics With and Without Symptoms of Peripheral Neuropathy
}

\author{
Dr. Suneetha. $\mathrm{G}^{1}$, Dr. Satyanarayana Prasad. $A^{2}$ \\ 1Assistant Professor of Physiology, NRI MC \& GH, Chinakakani, Guntur (Dt), AP, INDIA-522503; \\ 2Senior Resident, Department of General Surgery, NRI MC \& GH, Chinakakani, Guntur (Dt), AP. \\ *Corresponding author: *Dr Suneetha. $G$
}

\begin{abstract}
The pathogenesis of neuropathy in type 2 diabetes mellitus is multifactorial. This study is aimed to assess any association of dyslipidemias with peripheral neuropathy in type 2 diabetes mellitus. It also reveals any difference in lipid profile between asymptomatic (without symptoms of peripheral neuropathy) and symptomatic (with symptoms of peripheral neuropathy) subjects of diabetes mellitus.
\end{abstract}

Key words: Type 2 Diabetes mellitus, DPN, DN, Dyslipidemias, $H b A_{l c}$.

\section{Introduction}

Diabetes mellitus is a major public health problem worldwide. The World Health Organization has estimated that, the number of adults with diabetes in the world would increase alarmingly from 135million in 1995 to 300 million in $2025^{1}$. Type 2 diabetes, which is more than $90 \%$ of all diabetic cases, affects $5.9 \%$ of the world's adult population with almost $80 \%$ of the total in developing countries ${ }^{2}$. India leads the world with largest number of diabetic subjects earning the dubious distinction of being termed the "diabetes capital of the world"

The so called "Asian Indian Phenotype" refers to certain unique clinical and biochemical abnormalities in Indians which include increased insulin resistance, greater abdominal adiposity i.e., higher waist circumference despite lower body mass index, lower adiponectin and higher high sensitive C-reactive protein levels. At least a part of this is due to genetic factors. This term refers to the peculiar metabolic features of Asian Indians characterized by a propensity to excess visceral adiposity, dyslipidaemia with low HDL cholesterol, elevated serum triglycerides and increased small, dense LDL cholesterol, and an increased ethnic (possibly genetic) susceptibility to diabetes and premature coronary artery disease. However, the primary driver of the epidemic of diabetes is the rapid epidemiological transition associated with changes in dietary patterns and decreased physical activity as evident from the higher prevalence of diabetes in the urban population. The most disturbing trend is the shift in age of onset of diabetes to an younger age in the recent years, having long lasting adverse effects on nation's health and economy.

Genetic predisposition combined with life style changes, associated with urbanization and globalization, contribute to this rapid rise of diabetes in India ${ }^{3}$. It is known that almost $50 \%$ of people with diabetes remain undetected and hence some may even present with micro vascular and macro vascular complications at the time of diagnosis ${ }^{4,5}$.Chronic peripheral sensory motor symmetrical neuropathy (DPN) accounts for approximately $75 \%$ of the diabetic neuropathies ${ }^{6}$. It is defined as the presence of symptoms and/or signs of peripheral nerve dysfunction in people with diabetes mellitus, after exclusion of other causes ${ }^{7}$. The primary symptom of DPN is loss of sensation in the toes, which extends to involve the feet and leg in a stocking distribution. Some patients complain about numbness and pain, but the disease progresses most frequently insidiously and undetected. If no action is taken, foot callus, ulceration and infection might develop and further turn into distressing and painful impairment. The foot ulcers in diabetic patients mostly of neuropathic origin, and therefore eminently preventable ${ }^{8}$. Age, duration of diabetes and poor glycaemic control are recognised as risk factors for DPN, while cigarette smoking, hypertension, obesity, hyperlipidaemia and microalbuminuria has been pointed as potential risk indicators ${ }^{6}$. Although DPN may be asymptomatic and insidious in onset, neuropathic sensory symptoms may be complaints presented by the patient to the physician; therefore, they are clinically important.

MoazA et. al, reported that the diabetic neuropathy was significantly associated with age, duration of disease, negative association with arterial blood pressure, smoking status, low HDL cholesterol level, high triglyceride level, BMI and $\mathrm{HbAlc}^{9}$.Sothere are conflicting reports pertaining to role of duration, dyslipidaemias, $\mathrm{HbA}_{1} \mathrm{C}$ levels as causative factors of diabetic neuropathy. Against this backdrop the present study is intended to compare the levels of $\mathrm{HbA}_{1} \mathrm{c}$ and lipid profile between asymptomatic and symptomatic diabetic patients for neuropathy. 


\section{Materials \& Methods}

Study Design: A total number of 104 diabetic patients were selected for study. Out of them 52 subjects were symptomatic for neuropathy (symptomatic) and 52 subjects were asymptomatic for neuropathy (asymptomatics).

Study Setting: N.R.I. MEDICAL COLLEGE \& G.H, Chinakakani, Guntur, Andhra Pradesh.

For diagnosis of DN, bedside examination should include assessment of muscle power, sensations of pinprick, joint position, touch, and temperature. Vibration test should be done by tuning fork of a $128 \mathrm{~Hz}$. For touch sensation mono filament of 10 -g is recommended. Sensory examination should be performed on hands and feet bilaterally. The relevant laboratory parameters such as FBS, HbAlc, lipid profile were done in 52 diabetic subjects with symptoms and signs of neuropathy and 52 diabetic subjects without such symptoms and signs. The procedure was explained to all the subjects and written consent was obtained and was cleared by the institutional ethics committee. Standard test procedures were employed to collect the following laboratory data.

\section{Protocol for Biochemical parameters}

1. $\mathrm{HbA}_{1} \mathrm{C}$ by HPLC method on Biorad $\mathrm{D}_{10}$ with reference range of 4 to 6 .

2. Glucose by Hexokinase method on Dade dimensions - Seimens with reference range of $74-106 \mathrm{mg} / \mathrm{dl}$.

3. Triglycerides by Lipase / G - 01 Dehydrogenase method on Dade dimensions - Seimens with reference range of $<150 \mathrm{mg} / \mathrm{dl}$.

4. Cholesterol by cholesterol oxidase method on Dade dimensions - Seimens with reference range of $150-200$ $\mathrm{mg} / \mathrm{dl}$.

5. HDL by direct Non - Immunological method on Dade dimensions - Seimens with reference range of $35-60$ $\mathrm{mg} / \mathrm{dl}$.

6. LDL Cholesterol is derived by calculation using Friedwald's formula

All the above parameters before analysis were calibrated and the IQC is within \pm 1 S.D

STATISTICAL ANALYSIS: The collected data were tabulated (mean \pm S.D) in 2 categories. Results of mean age, mean duration, Fasting Blood Sugar (FBS), $\mathrm{HbA}_{1} \mathrm{C}$ and lipid profile are statistically compared between the two groups using student unpaired ' $t$ '- test. A 'p' value of $<0.05$ was considered significant.

\section{Results}

Table 1: Age wise stratification of diabetic patients - Asymptomatic and symptomatic for neuropathy:

\begin{tabular}{|l|l|l|}
\hline Age (yrs) & $\begin{array}{l}\text { No. of asymptomatic patients for } \\
\text { neuropathy }(\%)\end{array}$ & $\begin{array}{l}\text { No. of symptomatic patients for } \\
\text { neuropathy }(\%)\end{array}$ \\
\hline 40 to 50 & $8(15.39)$ & $23(44.23)$ \\
\hline 51 to 60 & $24(46.15)$ & $11(21.15)$ \\
\hline 61 to 70 & $16(30.77)$ & $11(21.15)$ \\
\hline 71 to 80 & $4(7.69)$ & $7(13.46)$ \\
Mean age \pm SD & $59.15 \pm 8.95$ & $56.13 \pm 12.18$ \\
\hline
\end{tabular}

Table 2: Duration of diabetes since first identified among study subjects

\begin{tabular}{|l|l|l|}
\hline Duration & $\begin{array}{l}\text { No. of asymptomatic patients for } \\
\text { neuropathy }(\%)\end{array}$ & $\begin{array}{l}\text { No. of symptomatic patients for neuropathy } \\
(\%)\end{array}$ \\
\hline$<5$ yrs & $16(30.77)$ & $14(26.92$ \\
\hline $5-10 \mathrm{yrs}$ & $34(65.38)$ & $35(67.31)$ \\
\hline$>10 \mathrm{yrs}$ & $2(3.85)$ & $3(5.77)$ \\
Mean duration $\pm \mathrm{SD}$ & $5.73 \pm 2.24$ & $6.27 \pm 2.37$ \\
\hline
\end{tabular}

Table 3: Comparison of biochemical parameters as mean values between asymptomatic and symptomatic groups.

\begin{tabular}{|l|l|l|l|}
\hline Biochemical parameters & $\begin{array}{l}\text { Asymptomatic diabetes patients } \\
\text { Mean } \pm \text { SD } \\
(\mathrm{n}=52)\end{array}$ & $\begin{array}{l}\text { Symptomatic diabetes patients } \\
\text { Mean } \pm \text { SD }(\mathrm{n}=52)\end{array}$ & ' $\mathrm{p}$ ' value \\
\hline $\mathrm{HbA}_{1} \mathrm{C}(\%)$ & $7.82 \pm 0.81$ & $7.60 \pm 0.90$ & $>0.05$ \\
\hline FBS $(\mathrm{mg} / \mathrm{dl})$ & $186.62 \pm 36.14$ & $184.87 \pm 35.99$ & $>0.05$ \\
\hline
\end{tabular}


Table 4: Comparison of lipid profile and lipid ratios as mean values between asymptomatic and symptomatic groups.

\begin{tabular}{|l|l|l|l|}
\hline Biochemical parameters & $\begin{array}{l}\text { Asymptomatic diabetes patients } \\
\text { Mean } \pm \text { SD } \\
(\mathrm{n}=52)\end{array}$ & $\begin{array}{l}\text { Symptomatic diabetes patients } \\
\text { Mean } \pm \text { SD }(\mathrm{n}=52)\end{array}$ & 'p' value \\
\hline TC (mg/dl) & $196.69 \pm 39.18$ & $189.07 \pm 31.9$ & $>0.05$ \\
\hline STGL (mg/dl) & $174.23 \pm 61.83$ & $156.01 \pm 60.59$ & $>0.05$ \\
\hline SLDL (mg/dl) & $127.77 \pm 25.47$ & $30.27 \pm 2.88$ & $>0.05$ \\
\hline HDL (mg/dl) & $32.19 \pm 3.05$ & $6.27 \pm 1.13$ & 0.005 \\
\hline TC/LDL & $1.54 \pm 0.08$ & $1.47 \pm 0.09$ & $<0.001$ \\
\hline TC/HDL & $6.13 \pm 1.20$ & $5.14 \pm 1.99$ & $<0.001$ \\
\hline TG/HDL & $5.42 \pm 1.88$ & $4.27 \pm 0.86$ & $>0.05$ \\
\hline LDL/HDL & $3.98 \pm 0.78$ & $>0.05$ & \\
\hline
\end{tabular}

\section{Discussion}

The cause of DN though remains unknown but ischaemic and metabolic components are implicated. Hyperglycaemia induces rheological changes, which increases endothelial vascular resistance and reduces nerve blood flow. Hyperglycaemia also causes depletion of nerve myoinositol through a competitive uptake mechanism. Moreover, activation of polyol pathway in the nerve through enzyme aldose reductase leads to accumulation of sorbitol and fructose in the nerve and induces non-enzymatic glycosylation of structural nerve proteins. Hyperglycaemia also induces oxidative stress. Activation of protein kinase $\mathrm{C}$ has been linked to vascular damage in DN. These changes result in abnormal neuronal, axonal, and Schwann cell metabolism, which result in impaired axonal transport. Direct measurement of glucose, sorbitol, and fructose in nerves of diabetic patients showed correlation with the severity of neuropathy. Endoneural hypoxia is produced by increased vascular resistance and reduced blood flow in the nerve. Hypoxia leads to further capillary damage, which in turn aggravates disturbance in axonal transport and reduced Na-K ATPase activity leading to axonal atrophy and impairment of nerve conduction. Unfortunately the basic research in DN has focused on carbohydrate metabolism; whereas amino acids, electrolytes, and lipid biochemical changes, which are associated with DM, have not been investigated with same vigour.

Complications of type 2 diabetes :Microvascular complications include nephropathy, retinopathy, and neuropathy andmacrovascular complications are primarily manifested by atherosclerosis and resulting cardiovascular morbidity and mortality. ${ }^{10,11}$ In both microvascular and macrovascular diabetic disease processes, the initial pathophysiologic step is believed to be tissue damage caused by hyperglycemia-mediated mitochondrial superoxide overproduction. ${ }^{11}$ However, from there, the mechanisms differ. The primary disease mechanism in diabetic macrovascular disease is atherosclerosis. Atherosclerosis is believed to begin with arterial wall injury, leading to chronic inflammation and immune cell infiltration, lipid deposition from lowdensity lipoprotein particles, and subsequent smooth muscle proliferation. The result is a fatty atherosclerotic lesion with a fibrous cap, that, when ruptured, may cause infarction ${ }^{12}$.In addition to the formation of atherosclerotic lesions, evidence suggests both increased platelet activity as well as a hypercoagulable state in type 2 diabetes. All of these factors increase the risk of thrombosis or thromboembolism. ${ }^{12}$

The mechanisms of action underlying diabetic microvascular disease do not involve atherosclerosis. Cells damaged by the aforementioned hyperglycemia-induced superoxide toxicity include those in the renal glomerulus, retina, and peripheral nerves. These cells are at increased risk because they are unable to regulate uptake of glucose in the hyperglycemic setting. ${ }^{13}$ Over a period of time, the result of such continued toxicity is nephropathy, retinopathy, and peripheral neuropathy.Measuring more downstream disease processes, such as superoxide activity, has the potential to refine our ability to identify patients at elevated risk for complications of type 2 diabetes. ${ }^{11}$

In our study mean age of symptomatics is 56 years while that of asymptomatics is 59 years. In 23 out of 52 i.e $44.23 \%$ of symptomatic subjects onset was early between $40-50$ years as shown in table -1 . Symptoms of PN manifested at a significantly lower age in our study. This is in agreement with Vondrova and coworkers in Czech, who found that diabetic polyneuropathy manifested at a younger age ${ }^{14}$. The mean duration of diabetics in both cases was between 5-10 years since first diagnosed as shown in table -2 . Expectedly both 
groups had high fasting blood sugar levels of comparable degree. The mean values as shown in table -3 are $186.62 \pm 36.14 \mathrm{mg} / \mathrm{dl}$ for asymptomatic subjects and $184.87 \pm 35.59 \mathrm{mg} / \mathrm{dl}$ for symptomatic subjects.

At the outset bed side neurological examination was carried out in all the subjects under study. Invariably neurological signs such as sluggish ankle jerk, gait disturbance, impaired vibration sense and other sensory defects were found in symptomatic patients. Asymptomatic subjects didn't reveal clinical signs of neurological deficiency. Biochemical parameters of both glycemic indicators and lipid profiles were estimated as shown in table -3 and $4 . \mathrm{HbA}_{1} \mathrm{c}$ represents a carbohydrate moiety attached to small portion of haemoglobin. It has many distinct fractions $\mathrm{A}_{1 \mathrm{a}}, \mathrm{A}_{1 \mathrm{~b}}, \mathrm{~A}_{1 \mathrm{c}}$. But $\mathrm{A}_{1 \mathrm{C}}$ fraction accounts for $60 \%$ of bound glucose and hence the significance of its estimation. Non diabetic individuals were said to have $\mathrm{HbA}_{1} \mathrm{c}$ values in the range of $3-6 \%{ }^{15}$. Glycosylated haemoglobin was estimated in all the subjects to evaluate the degree of glycemic control for the last $2-3$ months. It is because in sustained hyperglycemia of long standing, the proportion of $\mathrm{HbA}_{1} \mathrm{c}$ increases. Chronic hyperglycemia is said to promote diabetic neuropathy by varied mechanisms such as increased oxidative stress, decreased nitric oxide, impaired endothelial function ${ }^{16}$. The amount of glycosylated haemoglobin also correlates well with fasting and postprandial glucose levels ${ }^{17}$. The table -3 reveals poor glycemic control in almost equal measure in both the groups as indicated by elevated levels of $\mathrm{HbA}_{1}$ c i.e. $7.82 \pm$ 0.81 in asymptomatic subjects and $7.06 \pm 0.09$ in symptomatic subjects and elevated levels of FBS $186.62 \pm$ $36.14 \mathrm{mg} / \mathrm{dl}$ in asymptomatic group and $184.87 \pm 35.99 \mathrm{mg} / \mathrm{dl}$ in symptomatic group. As per a "research group" report in 1993, improved glycaemic control has been shown to prevent and delay progression of diabetic neuropathy emphasizing the importance of early diagnosis and aggressive management in these patients ${ }^{18}$.

The fasting serum lipid levels in asymptomatic and symptomatic patients of diabetic neuropathy were analyzed and shown in table - 4. National Cholesterol Education Programme (NCEP) ${ }^{19}$ had given certain guidelines defining normal limits of lipid levels. The value of Total Cholesterol (TC) exceeding $200 \mathrm{mg} / \mathrm{dl}$ is defined as hypercholesterolemia. Like wise LDL value exceeding $100 \mathrm{mg} / \mathrm{dl}$ and triglycerides (TGL) exceeding $150 \mathrm{mg} / \mathrm{dl}$ are abnormal. But HDL value of $\langle 40 \mathrm{mg} / \mathrm{dl}$ is unfavorable index of lipid profile. Dyslipidaemia was defined as by the presence of one or more abnormal serum lipid concentrations deviating from above values ${ }^{19}$. The significant features of lipid profile in table -4 are elevated levels of STGL, SLDL \& decline in HDL representing dyslipidaemia in both asymptomatic and symptomatic groups. Of these the decline in HDL is statistically significant between the two groups, ' $p$ ' value being 0.005 influenced by a great decline in symptomatic group. Their role in the causation of neuropathic symptoms needs further investigation. Interestingly total cholesterol in both cases is close to upper limit, particularly in asymptomatic diabetic patients. There is a statistically significant difference between TC / LDL \& TC / HDL ratios between the two groups. The variations in the ratios are on account of taking individual sample ratios in both groups rather than total mean ratios. Hence it is difficult to draw conclusions for the group as a whole from these ratios.

Diabetic dyslipidaemia is often associated with elevated triglycerides, LDL, total cholesterol and decreased HDL. Except for TC in our study all the three lipids are changing in abnormal direction. According to Bener A, Zirie M, hypertryglyceridemia is said to be the most common alteration of lipoproteins in type-II diabetes mellitus ${ }^{20}$. According to their postulation it is caused by hyperglycemia and insulin resistance by a variety of mechanisms such as over production of VLDL, TGL and defective clearance of VLDL, TGL and decreased activity of lipoprotein lipase and decreased production of apolipoprotein B. Also it was postulated that increased proportion of cholesterol, as a result of altered VLDL composition, increases the propensity for atherosclerosis ${ }^{15}$. Increased LDL is explained either by increased LDL production or decreased LDL clearance. Mild hyperglycemia is said to increase LDL production, while insulin resistance or relative insulin deficiency causes defects in LDL clearance. Greater susceptibility of LDL for oxidation is also said to play a major role in atherosclerotic process ${ }^{15}$. Regarding HDL, hyperglycemia causes increased activity of hepatic lipase which increases the clearance of HDL. While impaired catabolism of VLDL causes decreased formation of HDL ${ }^{15}$. This is said to be the reason for decreased levels of HDL in type-II diabetes mellitus ${ }^{15}$.

ChintamaniBodheet. al, found a link between dyslipidaemia and higher levels of $\mathrm{HbA}_{1} \mathrm{c}$ values ${ }^{17}$. There is no such association is found in our study. The ultimate analysis can be summarized that STGL and HDL cholesterol and ratio of TG/HDL reflect the balance between atherogenic and protective lipoproteins. There were no significant relation between diabetic neuropathy with sex and hyperlipidemia which is in agreement with the findings of Hillson et $\mathrm{al}^{21}$ and Master et $\mathrm{al}^{22}$. According to a research group, lipid profile (total serum cholesterol, HDL \& LDL cholesterol, fasting triglyceride) not effect the prevalence of peripheral neuropathy ${ }^{23}$. In our study also, there is no significant statistical difference in lipid profile except HDL, between asymptomatics and symptomatics for neuropathy.

\section{Conclusion}

There is no significant difference in lipid profile, between asymptomatics and symptomatics for peripheral neuropathy in diabetes except for HDL. 
But the ratio of total cholesterol to LDL cholesterol and total cholesterol to HDL cholesterol shows significant difference between asymptomatics and symptomatics

So there is no significant relation between Diabetic neuropathy with dyslipidemias and sex.However significantly high levels of HDL was observed in asymptomatic patients which needfurthur studies to ponder the probable protective role of HDL cholestrol.

\section{References}

[1]. King H, Aubert RE, Herman WH. Global burden of diabetes, 1995-2025: prevalence, numerical estimates, and projections. Diab Care 1998; 21(9): 1414-1431.

[2]. Sicree R, Shaw J, Zimmet P. Diabetes and impaired glucose tolerance in India. Diabetes Atlas. Gan D Ed. International Diabetes Federation, Belgium. International Diabetes Federation; 2006 p. 15-103.

[3]. Mohan V, Sandeep S, Deepa R, Shah B \& Varghese C. Epidemiology of type 2 diabetes: Indian scenario, Indian J Med Res 125, March 2007, pp 217-230.

[4]. Rema M, Deepa R, Mohan V. Prevalence of retinopathy at diagnosis among Type 2 diabetic patients attending a diabetic centre in South India. Br J Ophthalmol2000; 84 : 1058-1060.

[5]. Ramachandran A, Snehalatha C, Satyavani K, Latha E, Sasikala R, Vijay V. Prevalence of vascular complications and their risk factors in type 2 diabetes. J Assoc Physicians India 1999;47:1152- 1156.

[6]. Boulton AJ, Cavanagh PR, Rayman G. The foot in diabetes. $4^{\text {th }}$ Ed. John Wiley \& Sons Ltd; 2006.

[7]. Report and recommendations of San Antonio conference on diabetic neuropathy. Neurology 1988;38:1161-1165.

[8]. Boulton AJ, Vileikyte L, Ragnarson-Tennvall G, Apelqvist J. The global burden of diabetic foot disease. Lanset 2005;366:17191724.

[9]. Moaz A. Mojaddidi, MoutasemAboonq, Omar M AL Nozha,AbdulkadirAllam, Mohamed Fath EL-Bab. Early diagnosis of diabetic neuropathy in almadinahalmunawwarah,Journal of Taibah University Medical Sciences 2011; 6(2): 121-131.

[10]. Fowler MJ. Microvascular and Macrovascular Complications of Diabetes. Clin Diabetes. 2008;26:77-82.

[11]. Stolar M. Glycemic Control and Complications in Type 2 Diabetes Mellitus. Am J Med. 2010;123(suppl 3):S3-S11

[12]. Yesar MH Al - Shamma, Safaa Ali Khudhair, Mohammed Abbas Kadhim Al - Aridie. Prevalence of Peripheral Neuropathy in Type 2 Diabetic Patients. KufaMed.Journal 2011.VOL.14.No.2, $51-62$.

[13]. Tesfaye S, Chaturvedi N, Eaton SE, et al. Vascular risk factors and diabetic neuropathy. N Engl J Med 2005;352:341-350.

[14]. Vondrova H, Bartos V, Skibova J, et al. Factors affecting the incidence and severity of polyneuropathy in type 1 diabetes mellitus. CasLekCesk.1990;129(32):1004-1008.

[15]. Joslin's Diabetes Mellitus $14^{\text {th }}$ Ed Lippincott Williams \& Wilkins Chapter 33: General approach to the treatment of diabetes mellitus. pp. $567-571$.

[16]. Hoffman - snyder C, Smith BE, Ross MA, et al. Value of the Oral Glucose Tolerance Test in the Evaluation of Chronic Idiopathic Axonal Polyneuropathy. Arch Neural 2006;63:1075-1079.

[17]. ChintamaniBodhe, DeepaliJankar, Tara Bhutada, MilindPatwardhan, and VarshaPatwardhan. $\mathrm{HbA}_{1} \mathrm{c}$ : Predictor of Dyslipidemia and Atherogenecity in Diabetes Mellitus. Science Academy Publisher, U.K. Vol. 2, No.1,June 2012.

[18]. The Diabetes Control and Complications Trial Research Group. N Engl J Med 1993;329:977-986.

[19]. Ram VinodMahato, "Association between glycaemic control and serum lipid profile in type II diabetic patients: Glycatedhaemoglobin as dual biomarker", Bimedicalresearch., 2011,pp.375 - 380.

[20]. Bener A, Zirie M, "Lipids, lipoprotein (a) profile and $\mathrm{HbA}_{1} \mathrm{c}$ among Arabian type II diabetic patients", Biomedical research., 2007,pp. $97-102$

[21]. Hilson RM, Hockaday TDR, Newton DJ. Hyperglycemia is one correlate of deterioration in vibration sense during the 5-years after diagnosis of type 2 (noninsulin dependent ) diabetes. Diabetologia 1984;26:122-126.

[22]. Master RE, Steenkist AR, Dorman VK, et al. Epidemiological correlate of Diabetic neuropathy: report from the Pittsburgh Epidemiology of diabetic complications study.Diabetes 1989;38:1456-1461.

[23]. Yesar M.H. AI Shamma, Safaa Ali Khudhair DM, Mohammed Abbas Kadhim AI Aridie. Prevalence of Peripheral Neuropathy in Type 2 Diabetic patients. KufaMed.Journal 2011.VOL.14.No.2, 51-64

Dr. Suneetha G. "Comparison of Serum Lipid Profile in Diabetics With and Without Symptoms of Peripheral Neuropathy." IOSR Journal of Dental and Medical Sciences (IOSR-JDMS) 16.7 (2017): 17-21. 